\title{
Ophthalmia Secondary to Cobra Venom Spitting in the Volta Region, Ghana: A Case Report
}

\author{
Maria Andrea Lanzetta ${ }^{a, b} \quad$ Mihaela Cirtita $^{b, c} \quad$ Evelyn Aziebu $^{d}$ \\ Momodou Cham ${ }^{\mathrm{d}}$ Paolo Lanzetta ${ }^{\mathrm{b}, \mathrm{e}, \mathrm{f}}$ \\ ${ }^{a}$ Faculty of Medicine and Surgery, Università Vita-Salute San Raffaele, Milan, Italy; \\ ${ }^{b}$ Associazione Italiana Salute degli Occhi, Udine, Italy; ${ }^{\mathrm{c} A z i e n d a}$ Sanitaria Universitaria \\ Integrata di Udine, Udine, Italy; ${ }^{d}$ Comboni Hospital Sogakope, Sogakope, Ghana; \\ ${ }^{\mathrm{e}}$ Department of Medical and Biological Sciences - Ophthalmology, University of Udine,

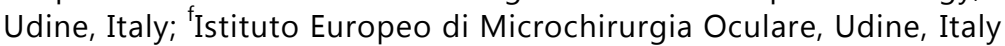

\section{Keywords}

Cobra venom · Ophthalmia · Ghana

\begin{abstract}
Purpose: To report the first case of ophthalmia due to contact with cobra venom in the Volta Region, Ghana. Methods: An ointment containing vitamin A was applied to treat the patient's unilateral defects in the corneal epithelium and the consequent diminished visual acuity. Results: Healing of the corneal epithelium and improvement of visual acuity were observed after only 1 day. Conclusions: This case suggests that consequences of cases of cobra venom spitting in the eyes can be minimal if immediate treatment is provided.
\end{abstract}

(C) 2017 The Author(s)

Published by S. Karger AG, Basel

\section{Introduction}

Different species of cobras defend themselves by spitting venom towards the face of whom they perceive as an aggressor [1]. Although rare, this event can lead to ocular envenomation with potentially serious injuries. Reported consequences range from periocular soft 
tissue swelling, hyperemia, extensive conjunctivitis, and corneal epithelial erosion to corneal opacity, uveitis, and hypopion, and even cranial nerve VII involvement [2-6].

Previous reports have highlighted the importance of an emergency therapeutic approach with multiple drugs to avoid severe complications such as necrosis of the eye $[3,6]$. However, in most cases a strict follow-up with early observation after the trauma is not available. Hereby, we describe the first case of eye involvement secondary to cobra spit in the Volta Region in Ghana with a close follow-up and an early resolution with a simple and affordable therapy.

\section{Case Description}

A 65-year-old male farmer presented to the eye clinic of the Comboni Hospital in Sogakope (Volta Region, Ghana) $1 \mathrm{~h}$ after having suffered an attack from a cobra that had spat venom in his eyes. The snake had been killed and identified as a Naja nigricollis, while the man's eyes and face had been promptly irrigated with tap water by his coworkers.

Upon examination, the patient's uncorrected visual acuity was 20/40 in the right eye and 20/70 in the left eye. The latter showed diffuse punctate corneal epithelial defects, conjunctival injection, and mild chemosis (Fig. 1), with no alterations of the anterior chamber and the fundus. The right eye and intraocular pressure on both sides were also normal.

The patient's left eye was treated solely with vitamin A ophthalmic ointment (Kerato VitA; Bruschettini, Genova, Italy) applied underneath a pressure patch. He was then instructed to come back for follow-up visits during the next 7 days.

These further examinations allowed an appreciation that on day 1 after injury the epithelial defect had healed completely (Fig. 2). In addition, the patient's left uncorrected visual acuity had improved to 20/40, and he no longer complained of any symptoms. During the following week, he did not develop any sequelae. Thus, the therapy was interrupted.

\section{Conclusion}

Direct ocular exposure to cobra venom spitting has been reported previously in a few dozen humans [2-6]. Cobras spread the venom over the entire face of the aggressor by rapidly moving their head, therefore enhancing the chance of hitting at least 1 eye [1]. As a consequence, various degrees of ocular and periocular injuries have been reported [2-6].

Cobra venom contains bioactive proteins such as neurotoxins, necrotoxins, and proteolytic enzymes that may damage ocular and periocular tissues and potentially produce a systemic effect $[3,6]$. This is why prompt and copious irrigation of the involved eyes is considered a mandatory maneuver.

Additionally, in most cases topical antibiotics, mydriatics, and cycloplegics are prescribed, while topical antivenom and heparin are rarely used. Administration and prescription of these types of drugs may be limited due to their poor availability in a rural setting. The therapy of choice should obviously depend on the severity of the presenting case and the possibility of performing a close follow-up.

In this case, 2 main factors were determinant in selecting the treatment. Firstly, our patient only showed mild symptoms such as punctate epithelial erosions and mild conjunctival involvement in the absence of any periocular swelling and intraocular inflammation. In addi- 
Lanzetta et al.: Ophthalmia Secondary to Cobra Venom Spitting in the Volta Region, Ghana: A Case Report

tion, we had the rare possibility of closely monitoring the patient for a week following the injury.

Based on these observations, it appears that in the absence of major intraocular reactive signs to the venom, a simple re-epithelization therapy may be sufficient to obtain early recovery. Our findings also support the general conviction that irrigation of the involved eyes is of crucial importance. Since such a simple procedure could be sight saving, we believe that a public education campaign should be issued on possible cobra spitting injuries to the eyes.

\section{Statement of Ethics}

The subject has given informed consent and the report has been approved by the institute's committee.

\section{Disclosure Statement}

None of the authors received any sponsorship or funding arrangements relating to this study and none of the authors have any conflicts of interest.

\section{References}

1 Berthé RA, Westhoff G, Bleckmann H: Potential targets aimed at by spitting cobras when deterring predators from attacking. J Comp Physiol A Neuroethol Sens Neural Behav Physiol 2013;199:335-340.

-2 Diop E, Beylot V, Berta C, Dugardin C, Aigle L: Droit dans les yeux!. Med Sante Trop 2015;25:131-132.

3 Goldman DR, Seefeld AW: Ocular toxicity associated with indirect exposure to African spitting cobra venom. Wilderness Environ Med 2010;21:134-136.

4 Warrell DA, Ormerod LD: Snake venom ophthalmia and blindness caused by the spitting cobra (Naja nigricollis) in Nigeria. Am J Trop Med Hyg 1976;25:525-529.

5 Chu ER, Weinstein SA, White J, Warrell DA: Venom ophthalmia caused by venoms of spitting elapid and other snakes: report of ten cases with review of epidemiology, clinical features, pathophysiology and management. Toxicon 2010;56:259-272.

6 Ang LJ, Sanjay S, Sangtam T: Ophthalmia due to spitting cobra venom in an urban setting: a report of three cases. Middle East Afr J Ophthalmol 2014;21:259-261. 
Case Reports in
Ophthalmology

Case Rep Ophthalmol 2017;8:99-103

DOI: $10.1159 / 000458519$

(c) 2017 The Author(s). Published by S. Karger AG, Basel www.karger.com/cop

Lanzetta et al.: Ophthalmia Secondary to Cobra Venom Spitting in the Volta Region, Ghana: A Case Report

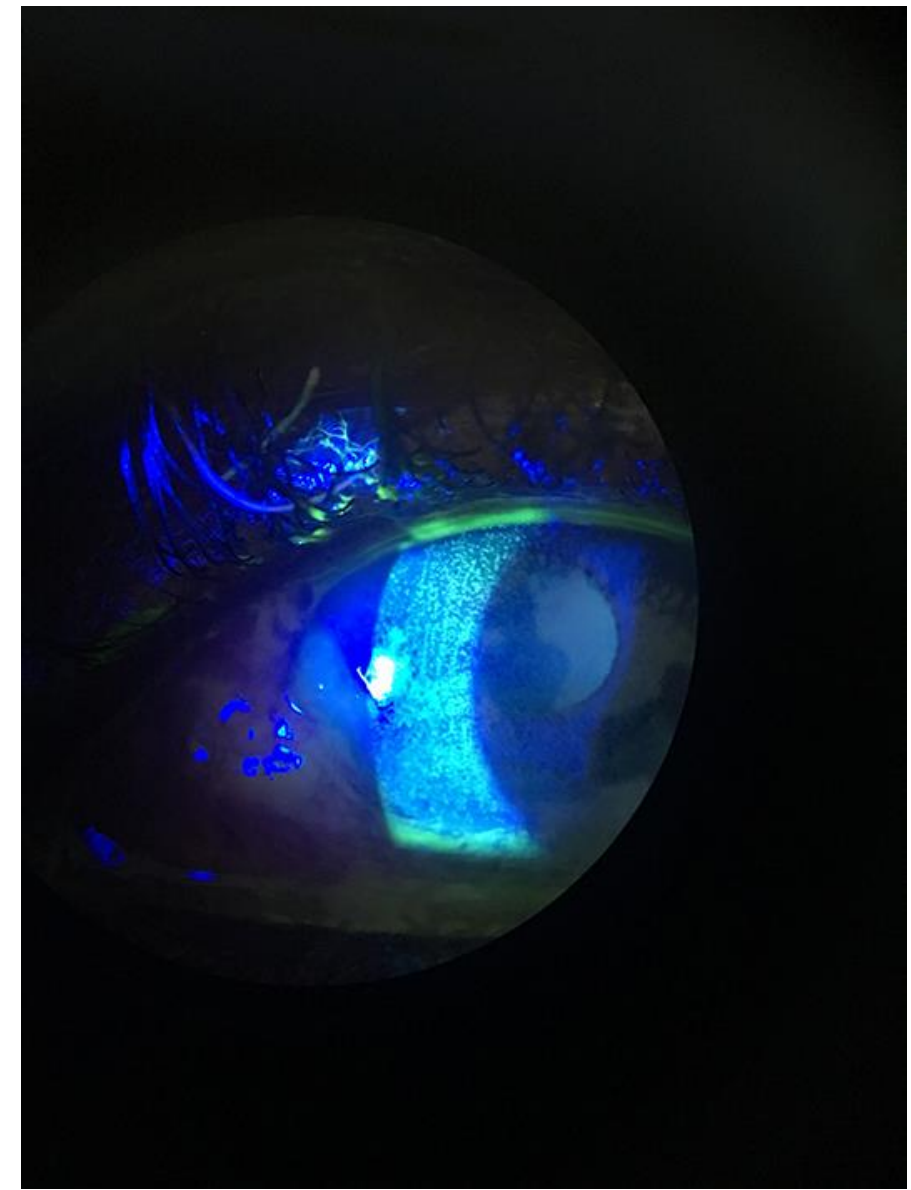

Fig. 1. Left eye at presentation with fluorescein staining showing epithelial erosions. 

www.karger.com/cop

Lanzetta et al:: Ophthalmia Secondary to Cobra Venom Spitting in the Volta Region, Ghana: A Case Report

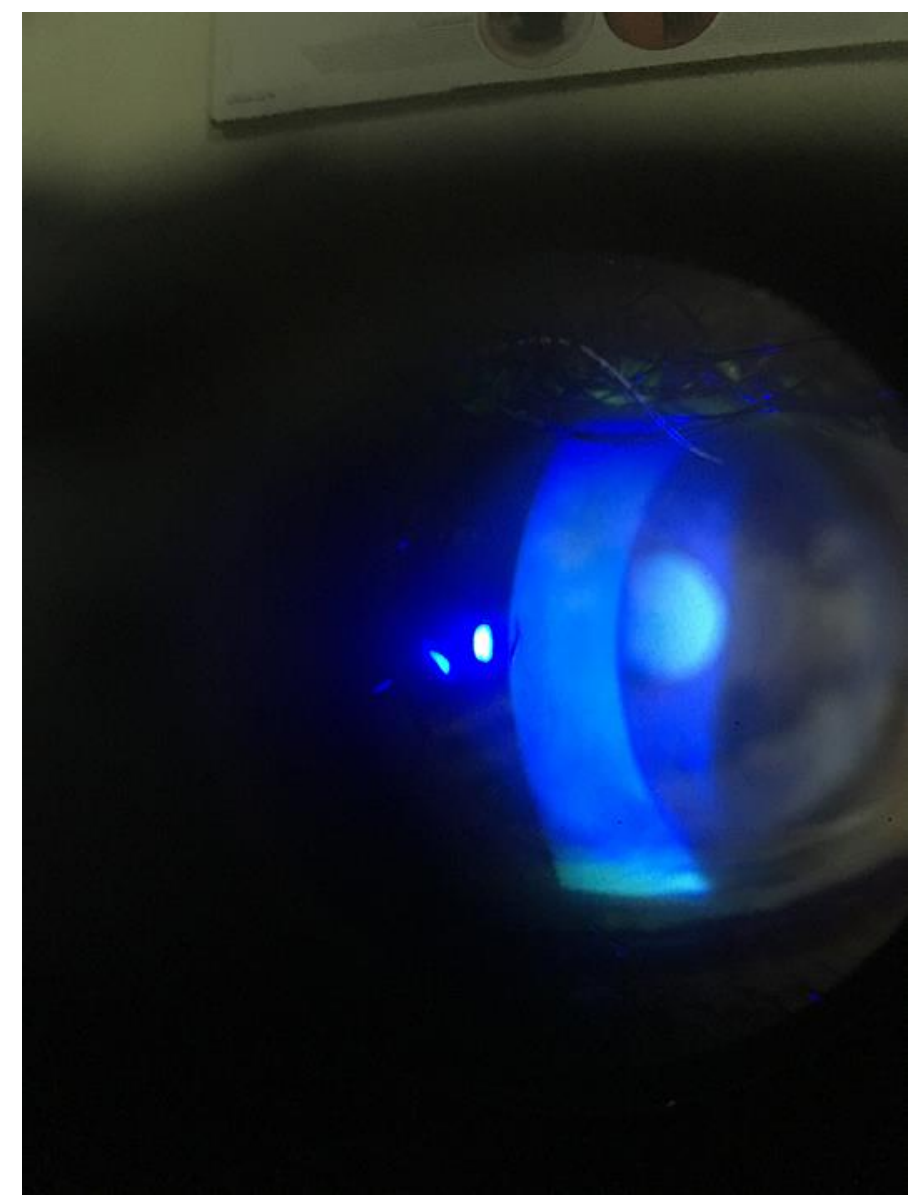

Fig. 2. Injured eye after 1 day. The epithelial defect has healed completely. 